\title{
Locating the second mesiobuccal canal in maxillary molars: challenges and solutions
}

This article was published in the following Dove Press journal:

Clinical, Cosmetic and Investigational Dentistry

\author{
Marcelo Santos Coelho' \\ Mariane Floriano Lopes \\ Santos Lacerda ${ }^{2}$ \\ Mauro Henrique Chagas \\ Silva ${ }^{3}$ \\ Marcos de Azevêdo Rios ${ }^{4}$ \\ 'São Leopoldo Mandic School of \\ Dentistry, Campinas, São Paulo, Brazil; \\ ${ }^{2}$ Department of Clinical Dentistry, \\ Federal University of Juiz de Fora, \\ Juiz de Fora, Minas Gerais, Brazil; \\ ${ }^{3}$ Univiçosa School of Dentistry, Minas \\ Gerais, Brazil; ${ }^{4}$ State University of \\ Feira de Santana, Feira de Santana, \\ Brazil
}

\begin{abstract}
The second mesiobuccal canal in mesiobuccal roots in maxillary molars is a common finding in root canal treatments. Failure on the location of these canals is associated with a high rate of unsuccessful treatments of maxillary molars. Its prevalence has been assessed in several in vitro and in vivo studies, presenting variations according to the methodology applied, along with the population of interest. While the anatomy of these teeth is well defined in micro-computed tomography studies, the clinical management is a great challenge for the practitioner. The use of a dental operating microscope has rendered a better clinical outcome when considering the location and treatment of this canal. On the other hand, cone-beam computed tomography use is still controversial in the efficacy of MB2 canal location. The association of a dental operating microscope with troughing performed with ultrasonic tips is an essential step in this location. Moreover, sodium fluorescein might be applied for root canal location. Due to the high rate of unsuccessful cases when the MB2 canal is not initially found, several cases are performed aiming to address the cases of missed MB2 canals. Therefore, the clinician should discuss the best possible approach, whether surgical or clinical. This article presents an overview of the importance of the MB2 canal on the outcomes of root canal treatments of maxillary molars. Solutions based in current literature will be presented accordingly.
\end{abstract}

Keywords: maxillary molar, root canal treatment, mesiobuccal root, mesiolingual canal, MB2 canal

\section{Introduction}

Anatomical complexities impose limitations to the chemico-mechanical preparation of the root canal, leading to areas not touched by the instrument, resulting in unsuccessful cases. Such complexities are of great importance, especially in maxillary molars. These teeth present a great variety in the number of main canals located in primary treatments. Previous clinical studies reported variation in distobuccal and palatal canals of maxillary molars. ${ }^{1,2}$ Particularly in the mesiobuccal root, very often a canal located in the lingual portion of such a root might not be located; this canal is known as the mesiolingual canal of the mesiobuccal root, mesiopalatal canal, or MB2 as a simplified name. ${ }^{3}$ The presence of such canals was first reported by Hess in $1925 .{ }^{4}$

The presence of the MB2 canal in maxillary first molars is said to range from $50 \%$ to $90 \%$ of cases. ${ }^{3,5}$ Knowledge of the morphology of the root canal system, therefore, is extremely important in planning endodontic therapy, as its success relies on the location of all of the canals that can then be disinfected, shaped, and filled. ${ }^{6}$

While in the past the periapical radiographs were the only image tool to aid in the location of canals, currently the use of cone-beam computed tomography (CBCT) has
Correspondence: Marcelo Santos Coelho Mandic, 13 - Pte. Preta, Rua Emilio Ribas 776/I3, Campinas, SP ZIP I3025-I4I, Brazil

Tel +55 199811। 6525

Email coelho_marcelo@yahoo.com.br 
become an important tool in this step. CBCT is a 3D radiographic image that promotes images with more sensitivity in the correlation of the images and real anatomy. ${ }^{7}$ In addition to high-resolution images, CBCT scans allow visualization of the images in axial, sagittal, and coronal views, aiding the detection of extra canals, anatomic variations, root resorptions, and pathologies that might affect hard tissues. ${ }^{8,9}$

Clinical tools have been applied to enhance the visualization and consequently increase the rate of MB2 location. Undoubtedly, dental operating microscopes associated with ultrasonic tips are considered the most helpful devices to locate extra canals. ${ }^{10}$ Moreover, experience of the operator, along with the time employed in the search of MB2 canals, combined with specific tools, is helpful in contributing to the clinical success of root canal location. ${ }^{11}$

Therefore, the aim of this article is to present by means of a literature review, followed by clinical cases, the importance of the location of MB2 canals. The challenges to locate such canals will be discussed as well as the relation of missing MB2 canals with failure cases. Solutions to locate such canals in primary cases and in non-surgical root canal treatments will be presented.

\section{Incidence of mesiolingual canals in mesiobuccal roots}

Within the scientific community, the existence of MB2 is already well known. However, the incidence of MB2 canal will strongly depend on the method applied for its location. Several studies have presented a broad variety of incidences of such canals, ranging from $14 \%$ to $94 \% .{ }^{3}$ Different in vitro methodologies have been used to assess the incidence of such canals: root sectioning with direct vision of the roots, use of microscopes, micro-CT, and CBCT scans.

Kulild and Peters assessed the internal anatomy of maxillary first molars using sectioning methodology. Their results showed an incidence of $94.1 \%$ MB2 canals in these teeth. ${ }^{3}$ According to Lyra et al, the root sectioning is more accurate than $\mathrm{CBCT}$ to reveal the internal anatomy of maxillary molars. ${ }^{12}$ It seems reasonable that direct visualization under magnification will lead to better results, as they are not subjected to artifacts. These in vitro studies are very accurate to reveal the histological aspects of root canal morphology; however, they are not clinically applicable.

Another study using micro-CT scans showed 100\% of MB2 canals in maxillary first molars and 57\% of MB2 canals in maxillary second molars. ${ }^{13}$ This study also showed that both micro-CT and CBCT are reliable to detect MB2 canals, while digital radiographs are not so accurate. Despite the importance of in vitro studies (root sectioning and micro$\mathrm{CT}$ ) evaluating the incidence of MB2 canals, their clinical application is limited. It is worthwhile to mention that the results of these laboratory studies usually present a higher rate of MB2 canals when compared to clinical findings. ${ }^{14}$

CBCT scans are part of the current armamentarium in modern endodontics. ${ }^{15}$ This image tool is important for diagnosing and planning steps of the treatment and paramount for cases with complex anatomy. Differences among the different machines and resolutions might lead to controversial results. ${ }^{16}$ When used for MB2 canals location, it seems that the voxel sizes of $0.125 \mathrm{~mm}$ and $0.200 \mathrm{~mm}$ are the most appropriate. ${ }^{17}$ Bauman et $\mathrm{al}^{16}$ showed $88.8 \%$ of positive findings for the $0.200 \mathrm{~mm}$ resolution and $93.3 \%$ for the $0.125 \mathrm{~mm}$ resolution, concluding that both are satisfactory for this location.

An in vitro study assessed the reliability of CBCT scans to detect MB2 canals when compared to root sectioning and direct visualization. ${ }^{17}$ This study showed that $68.4 \%$ of MB2 canals were detected when root sectioning was performed, and $57.9 \%$ of MB2 visualization was obtained with CBCT scans. Despite the conclusion of the authors that CBCT is a reliable tool to locate MB2 canals, the direct visualization of the root, followed by troughing, cannot be disregarded. Similar results were found in a recent in vivo study in which MB2 canals were located in some cases even when not seen in the CBCT scan. ${ }^{18}$

In fact, recently, several studies have demonstrated the incidence of MB2 canals using CBCT in different populations. Zhang et al found $52 \%$ of MB2 canals in maxillary first molars and $22 \%$ of MB2 canals in maxillary second molars, ${ }^{19}$ while other studies found MB2 canals in 74.5\% and 57.8\% of first and second maxillary in an Egyptian population; $73.6 \%$ and $56.2 \%$ in the Thai population; and $87.2 \%$ and $47.3 \%$ in the Spanish population, respectively. ${ }^{20-22}$ A recent systematic review has pointed to the presence of $\mathrm{MB} 2$ canals in $59.3 \%$ of maxillary first molars when CBCT is used for assessment. ${ }^{23}$ Overall, the aforementioned findings from CBCT studies have presented fewer MB2 canals than results obtained from in vivo studies.

Conclusions cannot be drawn when different populations are compared. Gio et $\mathrm{al}^{24}$ assessed the root canal morphology of maxillary molars in a North American population. The overall results of this study showed an incidence of $68.2 \%$ for first molars and $31.2 \%$ for second molars. It is noticeable that clinical studies, also in the North American population, found more canals than CBCT studies in the same population. Stropko ${ }^{11}$ found $93 \%$ of maxillary first molars presenting MB2 canals and $60.4 \%$ of maxillary second molars with such 
canals. Another recent study among graduate students found $70.5 \%$ of four canals in maxillary molars. ${ }^{25}$ Even among undergraduate students, the clinical incidence seems to be higher than CBCT studies (75.9\% in maxillary first molars and $56.9 \%$ in maxillary second molars). ${ }^{26} \mathrm{~A}$ common point in all of these previous studies is the magnification under dental operating microscopes, and either a long operation time for the endodontic specialist or supervision of experienced faculty. Therefore, we can infer that despite the great improvement achieved with the use of CBCT scans, several other tools cannot be disregarded when searching for MB2 canals. These strategies for detection of the MB2 include dentin removal under magnification, ultrasonic tips, observation of sodium hypochlorite bubbles, and color indicators.

\section{Locating the mesiobuccal canal in primary treatments}

Several factors might impact the location of MB2 canals in vivo. The clinician should be aware of these factors, anticipating the possibility of more difficulty in its location. Reis et $\mathrm{al}^{27}$ in a tomographic study, pointed to age as a factor that impacts the visualization of MB2 canals. In that study, patients ranging from 20 to 30 years had their canals visualized in $90.7 \%$ of the cases, while patients with ages ranging from 60 to 70 years had their canals visible in $81.9 \%$ of the cases. Another study that assessed root canal morphology using CBCT scans pointed out that full crown coverage is another factor that can prevent the location of MB2 canals. ${ }^{28}$ The use of statin for lowering cholesterol levels was demonstrated to lower the pulp chamber volume when compared to non-statin taking patients. ${ }^{29}$ Thus, one may infer that this medication is another factor that might impact root canal location.

Endodontic access is the first operatory step when locating root canals. This step should be completed with caution in order to preserve as much sound dentin as possible. Previous studies demonstrated that variations in the classical triangular shape of access in maxillary molars might help the location of root canals. ${ }^{30}$ Recently, a minimally invasive trend has gathered the attention of the endodontic community. ${ }^{31}$ This trend preaches that the minimum possible access should be performed in order to prevent tooth fracture, which is a catastrophic event. However, recent in vitro studies demonstrated that, after proper restoration, tooth resistance is not affected by the size of the access. Moreover, both location and instrumentation of the canals can be affected when a very small access is performed. ${ }^{32}$ Figure 1 presents a clinical situation of MB2 location in primary treatment.

The mesiobuccal root of maxillary molars frequently presents a flattening in the mesiodistal direction, leading to the presence of a second canal in this root. Therefore, it is possible to infer that internal morphology of teeth will

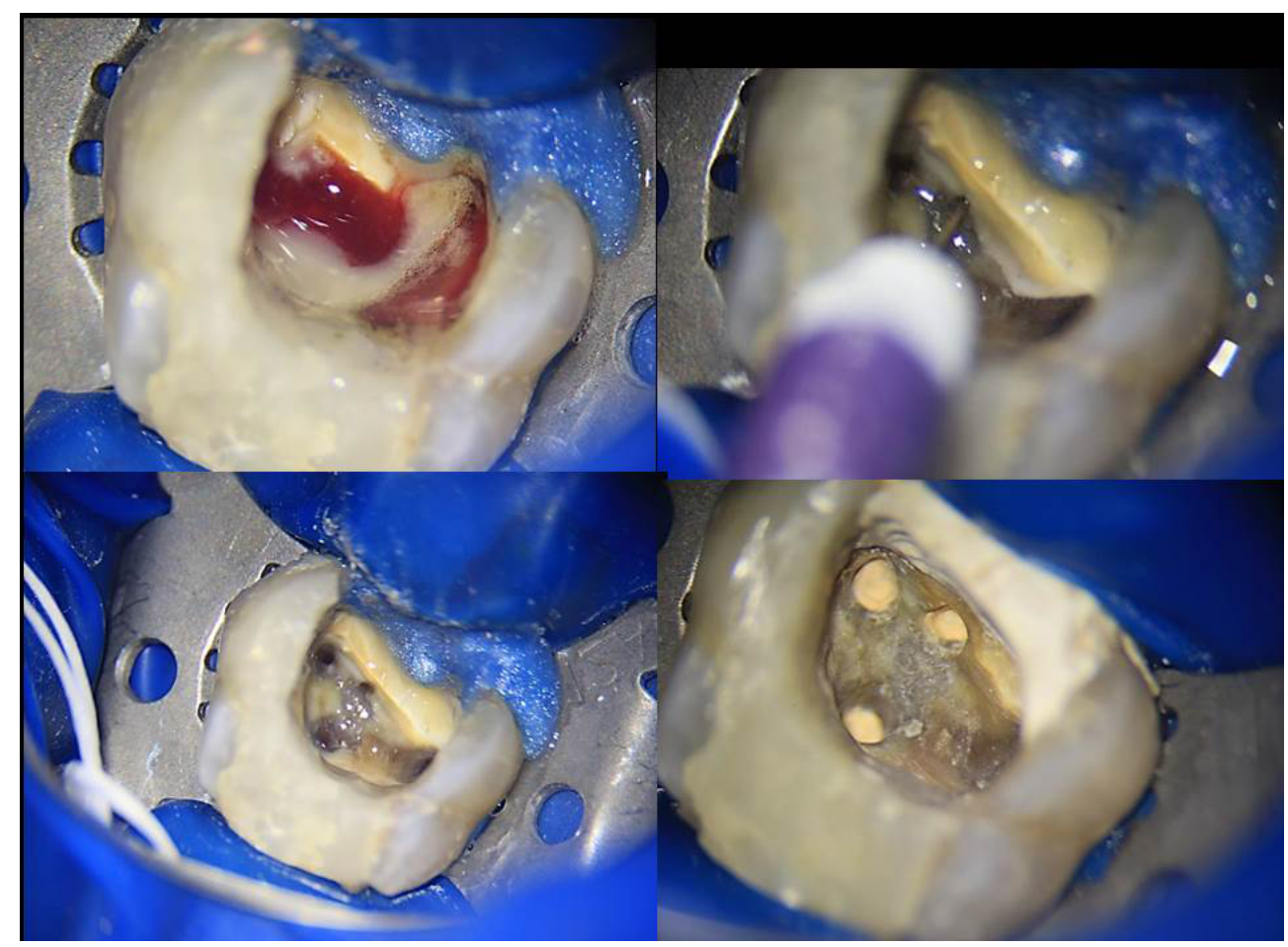

Figure I Typical finding of a MB2 canal in a maxillary molar presenting with irreversible pulpitis 
dictate the parameters with which the treatment should be performed, and its complexity will influence the results. This anatomy is complex due to some factors, such as the number of canals present in a root. The location of the MB2 canal is paramount for the success of treatment in maxillary molars. Several clinical steps might assist the provider to locate this canal, such as recognition of pulp chamber floor, magnification, ultrasonic tips, and dying.

Some morphological characteristics of the pulp chamber floor aid the location of the canals, thereby enhancing the outcomes. Usually the pulp chamber floor is darker than the pulp chamber walls and the pulp chamber roof. Those are usually whitish or yellowish, while the pulp chamber floor is gray. Lines in the pulp chamber floor lead to the entrance of the canals; these lines form a "map", also known as rostrum canalis. Following these lines with an endodontic explorer from the mesiobuccal to the palatal canal is a good manner to locate the MB2 canal, as it is usually located 2-3 mm from the mesiobuccal canal.

The use of $3.5 x$ loupes, joining magnification and illumination, is helpful to locate extra canals. ${ }^{33}$ Other studies, both in vitro and in vivo, have demonstrated the importance of the dental operating microscopes. ${ }^{34}$ However, the endodontic specialist cannot prevent the use of dental operating microscopes, enhancing the visualization of the canals without compromising the ergonomical aspects of dentistry. Moreover, microscopes are helpful in documenting the cases, as well as improving communication with patients and referral dentists. Despite the fact that the learning curve of the microscope is long, one study showed that at least 3 years of experience are necessary for its full achievement. ${ }^{34}$ However, its use is paramount for location of extra canals, including MB2 canals in maxillary molars.

Ultrasonic tips are other important tools in the endodontics armamentarium. Ultrasonic tips are able to remove pulp calcifications without excessive wear of the dentin. Diamond coated tips can be used for the removal of dentin shelves located over the MB2 canals. The use of these tips are preferable over burs because they can be used without preventing the visualization of the operatory field. ${ }^{35} \mathrm{~A}$ previous study showed that troughing the pulp chamber floor up to $2 \mathrm{~mm}$ from the palatal to the mesiobuccal canal is a helpful maneuver to locate MB2 canals. The benefits obtained with this step overcome the risk of perforation. ${ }^{18}$

During irrigation procedures with sodium hypochlorite, the clinician is able to observe bubble formation. These bubbles might indicate the reaction of the $\mathrm{NaOCl}$ with pulp tissue, releasing oxygen and thus indicating the possible location of the root canal entrance. This step can be performed during the whole treatment, aiming to observe of possible extra canals.

Nalapatti and Glassmann ${ }^{36}$ proposed the use of $1 \%$ sodium fluorescein for the location of extra canals. Fluorescein is an ophthalmic solution that binds to the connective tissue and shines when exposed to blue light. The solution is applied in the pulp chamber, remains for 2 minutes, and is then exposed to a blue curing light while the canals are observed under microscope. Based on this same principle, Pais et $\mathrm{al}^{37}$ attached a cobalt blue filter in a microscope. By doing so, the use of fluorescein could be done with the operator in the same chair position, maintaining the proper ergonomics of the operator. The in vitro results of Pais et $\mathrm{al}^{37}$ showed improvement of root canal location in maxillary first molars. There is a risk of tooth staining when fluorescein is applied, and for this reason the authors recommend the use of the solution for no more than 2 minutes and the copious irrigation of the pulp chamber with $\mathrm{NaOCl}$ after its use.

While the location of the MB2 canals is an extremely challenging situation, the preparation of these canals is not less difficult. There is a small risk of separation of hand instruments that should be taken into account. ${ }^{38}$ Recently, the use of reciprocating instruments was proven to properly clean these canals with minimal risk of incidents. ${ }^{39}$

\section{Retreatments}

When a root canal treatment fails, the clinician faces the challenge to make a decision that better solves the issue. Therefore, the proper diagnosis is mandatory for the clinical management of the situation. Moreover, finding the cause of the failure will better illustrate the situation to the patient and help him/her to take part in the decision process. Some situations are easily managed, such as short fillings in straight canals or under-instrumented roots. Others might require endodontic microsurgery such as long posts or separated instruments in the apical regions of curved canals. When post-removal is necessary, there is a risk of vertical root fracture. However, missed canals can be managed with either apical microsurgery or non-surgical root canal retreatment. Microsurgery studies are important to show the causes of failure in endodontically treated teeth. ${ }^{40}$ Overall, according to Song et al, missing canals are the second greatest cause of failure, being even more relevant than anatomical complexities, including underfilling of cracks. ${ }^{41}$ 


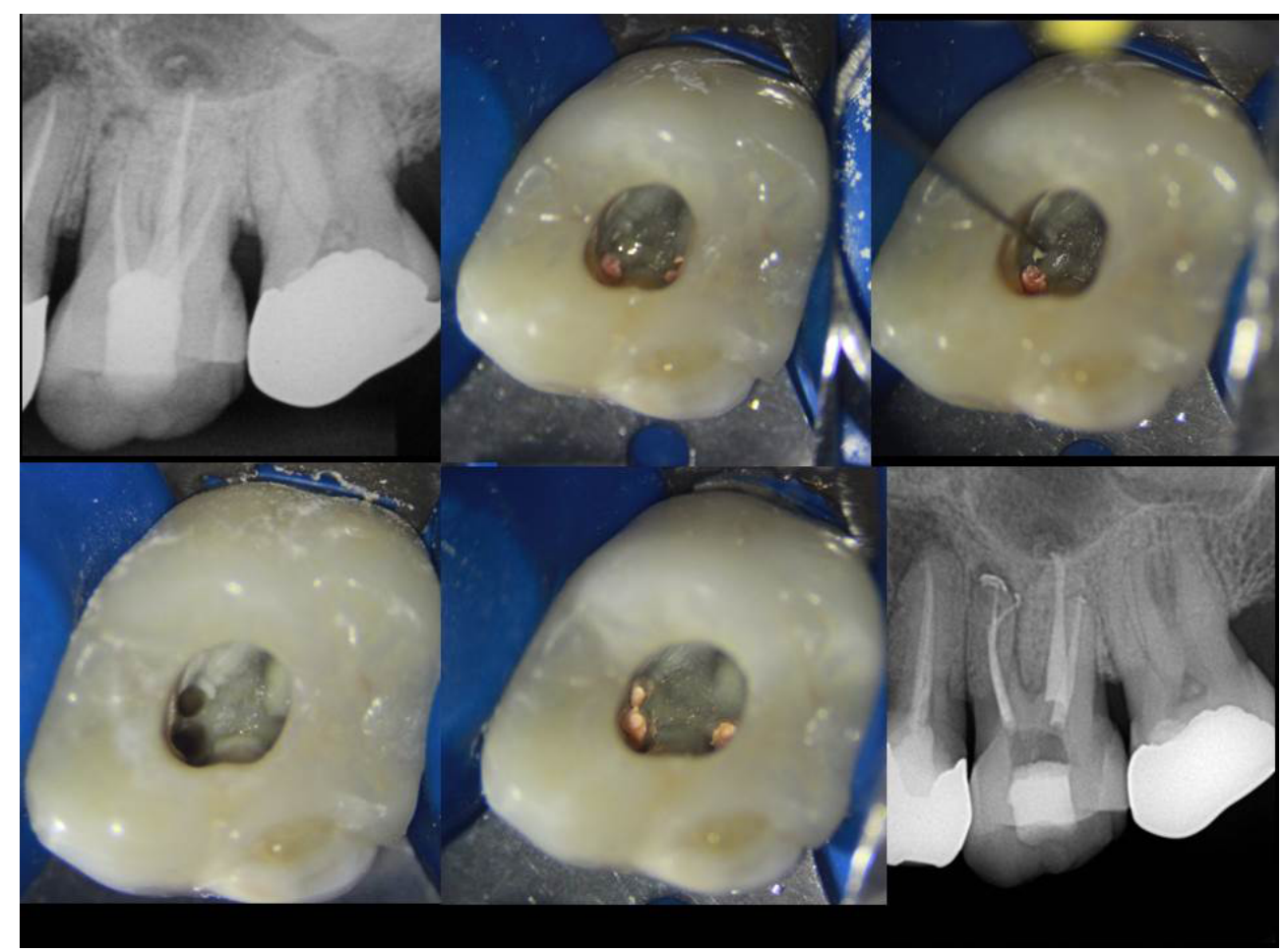

Figure 2 Location of a MB2 canal with the aid of magnification in a non-surgical root canal retreatment

Specifically when maxillary molars are involved, missing canals are responsible for a high rate of unsuccessful root canal treatments (Figure 2). A previous study demonstrated that missed canals are responsible for non-surgical retreatments in $42 \%$ of cases. In maxillary first molars, this incidence raises up to $48 \%$. Among those cases, $93 \%$ of them are located in the mesiobuccal root. ${ }^{42}$ In a study by Witherspoon et al, 35 out of the $58(60.34 \%)$ maxillary molars that required non-surgical root canal retreatment presented a missing canal as the main reason for failure. Missing canals might lead to continuous symptomatology and apical periodontitis. A recent study demonstrated that the higher presence of apical lesions was associated with missing MB2 canals in treatments performed without the use of a dental operating microscope. ${ }^{43}$

It is clear that the use of a dental operating microscope is mandatory in cases of non-surgical retreatments. However, the use of CBCT scans is still controversial in such cases..$^{18}$ It is our opinion that in these cases, unless an obvious failure is detected, its use is paramount. CBCT scans are more efficient in detecting MB2 canals when compared to $2 \mathrm{D}$ radiographs. Even when $3 \mathrm{D}$ radiographs cannot precisely point to the presence of MB2 canals, the position of the MB canal closer to the buccal wall can strongly suggest the presence of the MB2 canal (Figures 3 and 4). On the other hand, an axial view of the MB root showing a canal centralized in the root might rule out the presence of MB2 canals.

It is also important to emphasize the clinical importance of voxel size of the devices and the removal of root canal filling. ${ }^{44}$ Voxel sizes of $0.125 \mathrm{~mm}$ and $0.200 \mathrm{~mm}$ seem to be similar in showing the presence of MB2 canals. ${ }^{14}$ The voxel sizes of $0.300 \mathrm{~mm}$ and $0.400 \mathrm{~mm}$ are not as accurate. The presence of root filling might promote artifacts, decreasing the visualization of the canals. Despite the fact that no technique is able to completely remove root canal fillings, the reduction of these materials is very relevant. ${ }^{45}$ Therefore, our rationale recommends the removal of the root filling prior to the CBCT scan. Eventually, CBCT can be unnecessary as the clinical steps are able to locate the canal.

It can be concluded that the proper location and treatment of MB2 canals are essential for the success of treatment of maxillary molars. The clinician should be able to locate and manage these cases in primary treatments and also choose the best option when the initial treatment fails. Domain of anatomy, use of dental operating microscopes, and management of CBCT images must be the minimum competencies of a competent endodontist. 


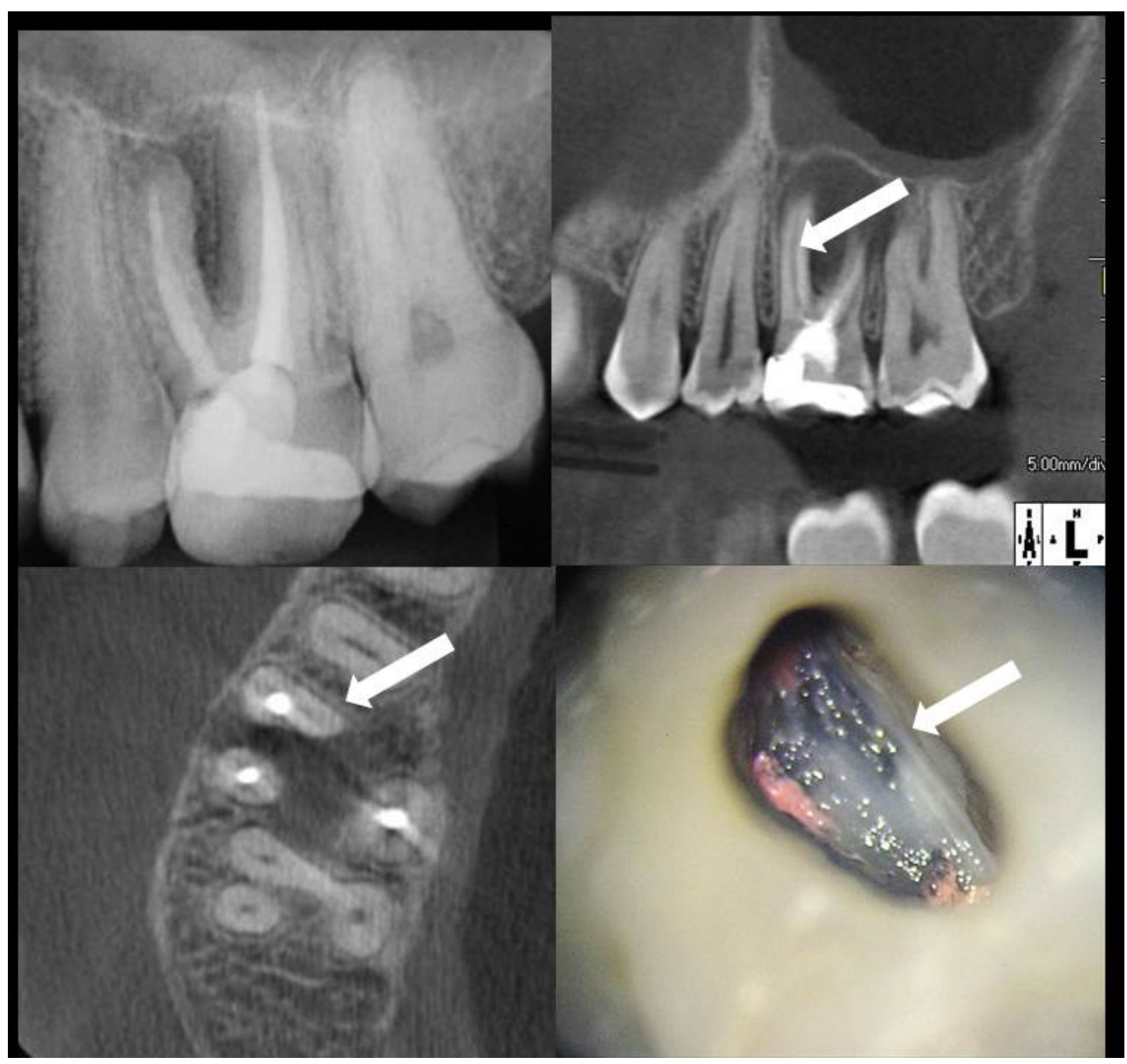

Figure 3 Symptomatic apical periodontitis due to a missing MB2 canal. The arrows are pointing to the MB2 canal in the CBCT scan and clinical aspects

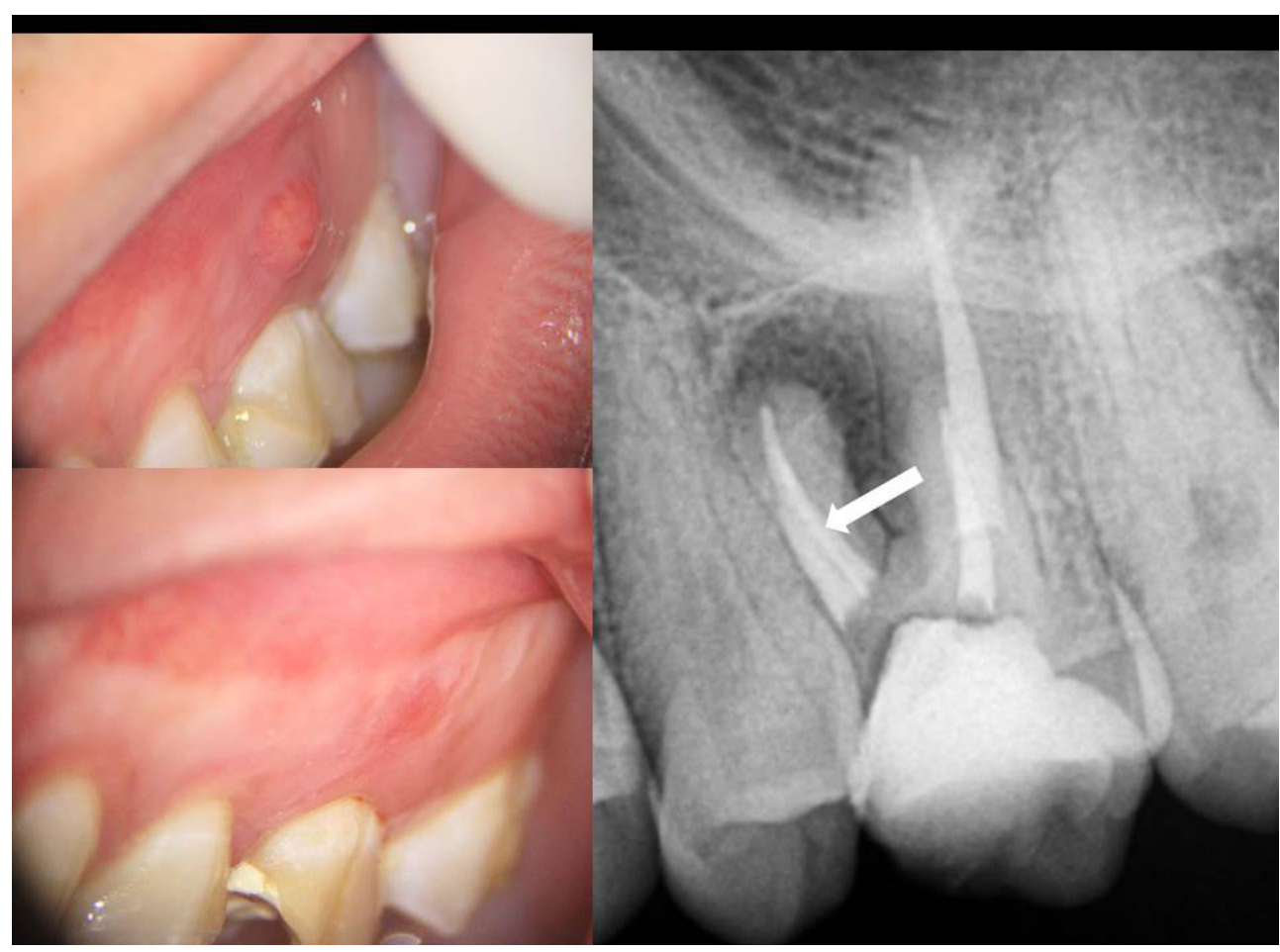

Figure 4 Resolution of the sinus tract in the previous case; the arrow is pointing to the MB2 canal in the final 2-D radiograph 


\section{Disclosure}

The authors report no conflicts of interest in this work

\section{References}

1. Christie WH, Peikoff MD, Fogel HM. Maxillary molars with two palatal roots: a retrospective clinical study. J Endod. 1991;17(2):80-84.

2. Fogel HM, Cunha RS. Maxillary First Molars with 2 Distobuccal Canals: A Case Series. J Endod. 2017;43(11):1925-1928.

3. Kulild JC, Peters DD. Incidence and configuration of canal systems in the mesiobuccal root of maxillary first and second molars. $J$ Endod. 1990;16(7):311-317.

4. Ibarrola JL, Knowles KI, Ludlow MO, Mckinley IB. Factors affecting the negotiability of second mesiobuccal canals in maxillary molars. J Endod. 1997;23(4):236-238.

5. Hiebert BM, Abramovitch K, Rice D, Torabinejad M. Prevalence of Second Mesiobuccal Canals in Maxillary First Molars Detected Using Cone-beam Computed Tomography, Direct Occlusal Access, and Coronal Plane Grinding. J Endod. 2017;43(10):1711-1715.

6. Baratto Filho F, Zaitter S, Haragushiku GA, de Campos EA, Abuabara A, Correr GM. Analysis of the internal anatomy of maxillary first molars by using different methods. $J$ Endod. 2009;35(3):337-342.

7. Nikoloudaki GE, Kontogiannis TG, Kerezoudis NP. Evaluation of the Root and Canal Morphology of Maxillary Permanent Molars and the Incidence of the Second Mesiobuccal Root Canal in Greek Population Using Cone-beam Computed Tomography. Open Dent J. 2015;9:267-272.

8. Estrela C, Rabelo LE, de Souza JB, et al. Frequency of Root Canal Isthmi in Human Permanent Teeth Determined by Cone-beam Computed Tomography. J Endod. 2015;41(9):1535-1539.

9. Estrela C, Bueno MR, Leles CR, Azevedo B, Azevedo JR. Accuracy of cone beam computed tomography and panoramic and periapical radiography for detection of apical periodontitis. J Endod. 2008;34(3):273-279.

10. de Carvalho MC, Zuolo ML. Orifice locating with a microscope. J Endod. 2000;26(9):532-534.

11. Stropko JJ. Canal morphology of maxillary molars: clinical observations of canal configurations. J Endod. 1999;25(6):446-450.

12. Lyra CM, Delai D, Pereira KC, Pereira GM, Pasternak Júnior B, Oliveira CA. Morphology of Mesiobuccal Root Canals of Maxillary First Molars: a comparison of CBCT scanning and Cross-sectioning. Braz Dent $J$. 2015;26(5):525-529.

13. Domark JD, Hatton JF, Benison RP, Hildebolt CF. An ex vivo comparison of digital radiography and cone-beam and micro computed tomography in the detection of the number of canals in the mesiobuccal roots of maxillary molars. J Endod. 2013;39(7):901-905.

14. Cleghorn BM, Christie WH, Dong CC. Root and root canal morphology of the human permanent maxillary first molar: a literature review. J Endod. 2006;32(9):813-821.

15. Patel S, Durack C, Abella F, Shemesh H, Roig M, Lemberg K. Cone beam computed tomography in Endodontics - a review. Int Endod $J$. 2015;48(1):3-15.

16. Bauman R, Scarfe W, Clark S, Morelli J, Scheetz J, Farman A. Ex vivo detection of mesiobuccal canals in maxillary molars using CBCT at four different isotropic voxel dimensions. Int Endod J. 2011;44(8):752-758.

17. Blattner TC, George N, Lee CC, Kumar V, Yelton CD. Efficacy of conebeam computed tomography as a modality to accurately identify the presence of second mesiobuccal canals in maxillary first and second molars: a pilot study. J Endod. 2010;36(5):867-870.

18. Parker J, Mol A, Rivera EM, Tawil P. CBCT uses in clinical endodontics: the effect of CBCT on the ability to locate MB2 canals in maxillary molars. Int Endod J. 2017;50(12):1109-1115.

19. Zhang R, Yang H, Yu X, Wang H, Hu T, Dummer PM. Use of CBCT to identify the morphology of maxillary permanent molar teeth in a Chinese subpopulation. Int Endod J. 2011;44(2):162-169.

20. Ghobashy AM, Nagy MM, Bayoumi AA. Evaluation of Root and Canal Morphology of Maxillary Permanent Molars in an Egyptian Population by Cone-beam Computed Tomography. JEndod. 2017;43(7):1089-1092.
21. Ratanajirasut R, Panichuttra A, Panmekiate S. A Cone-beam Computed Tomographic Study of Root and Canal Morphology of Maxillary First and Second Permanent Molars in a Thai Population. J Endod. 2018;44(1): $56-61$.

22. Pérez-Heredia M, Ferrer-Luque CM, Bravo M, Castelo-Baz P, RuízPiñón M, Baca P. Cone-beam Computed Tomographic Study of Root Anatomy and Canal Configuration of Molars in a Spanish Population. J Endod. 2017;43(9):1511-1516.

23. Corbella S, del Fabbro M, Tsesis I, Taschieri S. Computerized tomography technique for the investigation of the maxillary first molar mesiobuccal root. Int J Dent. 2013;2013:614898-6.

24. Guo J, Vahidnia A, Sedghizadeh P, Enciso R. Evaluation of root and canal morphology of maxillary permanent first molars in a North American population by cone-beam computed tomography. $J$ Endod. 2014;40(5):635-639.

25. Hartwell G, Appelstein CM, Lyons WW, Guzek ME. The incidence of four canals in maxillary first molars: a clinical determination. $J \mathrm{Am}$ Dent Assoc. 2007;138(10):1344-1346.

26. Coelho MS, Parker JM, Tawil PZ. Second Mesiobuccal Canal Treatment in a Predoctoral Dental Clinic: A Retrospective Clinical Study. J Dent Educ. 2016;80(6):726-730.

27. Reis AG, Grazziotin-Soares R, Barletta FB, Fontanella VR, Mahl CR. Second canal in mesiobuccal root of maxillary molars is correlated with root third and patient age: a cone-beam computed tomographic study. J Endod. 2013;39(5):588-592.

28. Studebaker B, Hollender L, Mancl L, Johnson JD, Paranjpe A. The Incidence of Second Mesiobuccal Canals Located in Maxillary Molars with the Aid of Cone-beam Computed Tomography. J Endod. 2018;44(4):565-570.

29. Pettiette MT, Zhong S, Moretti AJ, Khan AA. Potential correlation between statins and pulp chamber calcification. $J$ Endod. 2013;39(9):1119-1123.

30. Weller RN, Hartwell GR. The impact of improved access and searching techniques on detection of the mesiolingual canal in maxillary molars. J Endod. 1989;15(2):82-83.

31. Clark D, Khademi JA. Case studies in modern molar endodontic access and directed dentin conservation. Dent Clin North Am. 2010;54(2): 275-289.

32. Rover G, Belladonna FG, Bortoluzzi EA, de-Deus G, Silva E, Teixeira CS. Influence of Access Cavity Design on Root Canal Detection, Instrumentation Efficacy, and Fracture Resistance Assessed in Maxillary Molars. J Endod. 2017;43(10):1657-1662.

33. Hasan M, Raza Khan F. Determination of frequency of the second mesiobuccal canal in the permanent maxillary first molar teeth with magnification loupes $(\times 3.5)$. Int J Biomed Sci. 2014;10(3): 201-207.

34. Bowers DJ, Glickman GN, Solomon ES, He J. Magnification's effect on endodontic fine motor skills. J Endod. 2010;36(7):1135-1138.

35. Plotino G, Pameijer CH, Grande NM, Somma F. Ultrasonics in endodontics: a review of the literature. $J$ Endod. 2007;33(2):81-95.

36. Nallapati S, Glassman G. The use of ophthalmic dye in root canal location. Endod Pract. 2004;15:1-6.

37. Pais ASG, Deo AV, de Martin AS, Cunha RS, Fontana CE, Bueno CES. Sodium fluorescein and cobalt blue filter coupled to a dental operating microscope to optimise root canal location in maxillary first molars. Endo. 2014;8(3):193-198.

38. Coelho MS, Card SJ, Tawil PZ. Safety Assessment of Two Hybrid Instrumentation Techniques in a Dental Student Endodontic Clinic: A Retrospective Study. J Dent Educ. 2017;81(3):333-339.

39. Zuolo ML, Carvalho MC, de-Deus G. Negotiability of Second Mesiobuccal Canals in Maxillary Molars Using a Reciprocating System. J Endod. 2015;41(11):1913-1917.

40. Tawil PZ, Saraiya VM, Galicia JC, Duggan DJ. Periapical microsurgery: the effect of root dentinal defects on short- and long-term outcome. J Endod. 2015;41(1):22-27.

41. Song M, Kim HC, Lee W, Kim E. Analysis of the cause of failure in nonsurgical endodontic treatment by microscopic inspection during endodontic microsurgery. $J$ Endod. 2011;37(11):1516-1519. 
42. Witherspoon DE, Small JC, Regan JD. Missed canal systems are the most likely basis for endodontic retreatment of molars. Tex Dent J. 2013;130(2):127-139.

43. Khalighinejad N, Aminoshariae A, Kulild JC, Williams KA, Wang J, Mickel A. The Effect of the Dental Operating Microscope on the Outcome of Nonsurgical Root Canal Treatment: A Retrospective Casecontrol Study. J Endod. 2017;43(5):728-732.
44. Vizzotto MB, Silveira PF, Arús NA, Montagner F, Gomes BP, da Silveira HE. CBCT for the assessment of second mesiobuccal (MB2) canals in maxillary molar teeth: effect of voxel size and presence of root filling. Int Endod J. 2013;46(9):870-876.

45. Rios MA, Villela AM, Cunha RS, et al. Efficacy of 2 reciprocating systems compared with a rotary retreatment system for gutta-percha removal. J Endod. 2014;40(4):543-546.

\section{Publish your work in this journal}

Clinical, Cosmetic and Investigational Dentistry is an international, peer-reviewed, open access, online journal focusing on the latest clinical and experimental research in dentistry with specific emphasis on cosmetic interventions. Innovative developments in dental materials, techniques and devices that improve outcomes and patient satisfac- tion and preference will be highlighted. The manuscript management system is completely online and includes a very quick and fair peerreview system, which is all easy to use. Visit http://www.dovepress. com/testimonials.php to read real quotes from published authors. 